\title{
Short Communication: \\ Detection of Salmonella typhimurium ATCC 14028 and Listeria monocytogenes ATCC 7644 in processed meat products using Real- Time PCR Multiplex Method
}

\author{
ALFI SOPHIAN $^{1, \bullet}$, RATNA PURWANINGSIH $^{1}$, EKA PUTRI JUNIARTI IGIRISA ${ }^{1}$, \\ MUHAMMAD LUTHFI AMIRULLAH ${ }^{1}$, BERTHA LOLO LUKITA ${ }^{2}$, RISKA ADRIANI FITRI ${ }^{2}$ \\ ${ }^{1}$ Laboratory of Microbiology and Molecular Biology, Indonesian National Agency of Drug and Food Control. Jl. Tengah Toto Selatan, Bone Bolango \\ 96123, Gorontalo, Indonesia. Tel./fax.: +62-435-822052, `email: alfi.sophian@pom.go.id \\ ${ }^{2}$ National Food and Drug Testing Development Center. Jl. Percetakan Negara No. 23, Jakarta Pusat 10560, Jakarta, Indonesia. \\ Tel.: +62-21-4244691,4245057, Fax.: +62-21-4245150, 4201427.
}

Manuscript received: 17 July 2020. Revision accepted: 10 January 2021.

\begin{abstract}
Sophian A, Purwaningsih R, Igirisa RPJ, Amirullah ML, Lukita BL, Fitri RA. 2021. Short Communication: Detection of Salmonella typhimurium ATCC 14028 and Listeria monocytogenes ATCC 7644 in processed meat products using Real-Time PCR Multiplex Method. Asian J Nad Prod Biochem 19: 17-20. The detection of Salmonella typhimurium ATCC 14028 and Listeria monocytogenes ATCC 7644 in processed meat products was carried out using Multiplex Real-Time PCR (qPCR) in the Microbiology and Molecular Biology Laboratory at the Indonesian Food and Drug Authority in Gorontalo. The purpose of this study was to provide alternative testing methods for food products circulating in the market. The sample consisted of 25 samples of processed meat products spike with Salmonella typhimurium ATCC 14028 phase 2 and Listeria monocytogenes ATCC 7644 phase 2. The method used in the study was qPCR analysis using the SYBR Green method, while DNA isolation used the direct PCR method. Data analysis was carried out based on Cycle threshold and Melting temperature based on two main criteria. Cycle threshold (Ct) analysis determines the sample's $\mathrm{Ct}$ value and compares it with the control. Melting temperature (Tm) analysis determines the temperature at which 50\% of doublestranded DNA changed to a single standard and compares it with the melting temperature of positive control. The results showed Salmonella typhimurium ATCC 14028 in the processed meat was detected at an average Ct value of 10.34 and a Tm value of 85.70 . The presence of Listeria monocytogenes ATCC 7644 in the samples was recognized at an average Ct value of 14.04 and an average Tm value of 80.07. It can be concluded that the real-time multiplex PCR method can be used to detect Salmonella typhimurium ATCC 14028 and Listeria monocytogenes ATCC 7644 by using the melting curve (Tm) analysis.
\end{abstract}

Keywords: Listeria monocytogenes, Multiplex PCR, qPCR, Salmonella typhimurium

Abbreviations: TSA: Tryptic Soy Agar, TSB: Tryptic Soy Broth

\section{INTRODUCTION}

Indonesia has a variety of foods derived from processed meat, including shredded meatballs, rendang, beef jerky, sausages, nuggets, etc. The biggest challenge in serving healthy and hygienic foods is food preparations free from bacterial contamination. The primary source of bacterial contamination of processed meat is the cleanliness of raw materials. A study by Sugiyoto et al. (2015) showed that the origins of microbial contamination in traditional markets originated from water used to clean hands or butcher knives.

Contamination of Salmonella typhimurium and Listeria monocytogenes in food can result in "foodborne disease," i.e., diseases caused by consuming contaminated food or drink. Therefore, it is necessary to obtain the method for pathogenic bacteria using molecular techniques. Among the molecular methods often used to detect pathogenic bacteria is polymerase change reaction (PCR), i.e., Realtime PCR analysis (qPCR) (Oliveira et al. 2018). Molecular analysis for the detection of pathogenic bacteria using realtime PCR has advantages compared to conventional methods. The average time required for bacterial identification was 50-52 hours by the direct PCR method (24 hours for sample enrichment, 24 hours for selective enrichment, and 1.5 hours for real-time PCR analysis).

One of the real-time PCR methods is the Multiplex PCR technique. The first use of Multiplex PCR was in 1988 to detect the deletions in the dystrophin gene (Chamberlain et al. 1988). In 2008, multiplex PCR was used to analyze microsatellites and SNPs (Hayden et al. 2008). The procedures and components in a multiplex PCR reaction are the same as a regular PCR. However, the amplification process is carried out simultaneously by reading several gene targets in a single analysis. Multiplex PCR contains various sets of primers with a mixture of single PCR reagents to produce amplicons of varying sizes specific to different DNA sequences (Chamberlain et al. 1988). Research on the application of the multiplex PCR technique to bacteria was carried out by Gosiewski et al. 
(2012), who applied seven different target genes from the B. streptococci strain. It was also carried out on several bacteria that cause foodborne diseases, such as $E$. coli and Coliform (Molina et al. 2015).

Regulation of The FDA (BPOM) of the Republic of Indonesia No. 13 of 2019 concerning the Requirements for Maximum Limits of Microbiological Contamination. It regulates the contamination limits of pathogenic bacteria in food products. The category of meat and meat products (referred to as hunted animals) does not allow to contain pathogenic Salmonella. Therefore, product monitoring is crucial to ensure that the circulating products are free from pathogenic bacterial contaminants.

This study was conducted to develop alternative methods for detecting Salmonella typhimurium and Listeria monocytogenes in processed meat products. This study's results might be used as an improved method to detect Salmonella typhimurium and Listeria monocytogenes in processed meat products based on the molecular test.

\section{MATERIALS AND METHODS}

\section{Materials}

Twenty-five samples of processed meat (meatball, jerky, sausage, beef burger, shredded), Tryptic Soy Broth (TSB) enrichment media, Tryptic Soy Agar (TSA) / Nutrient Agar (NA), QuantiNova SYBR Green PCR kit (Qiagen).

\section{Sample setup}

Twenty-five samples of processed meat products were spiked with positive control of Salmonella typhimurium ATCC 14028 phase 2 and Listeria monocytogenes ATCC 7644 phase 2

\section{Isolation from enriching media}

Weigh 10 grams of processed meat, then add $90 \mathrm{~mL}$ of Tryptic Soy Broth (TSB). Incubate at $35-37^{\circ}$ for $18-24$ hours. After incubation, scratch one loopful on the TSA or NA agar medium, then incubate at $35-37^{\circ}$ for $18-24$ hours.

\section{DNA isolation}

DNA isolation was carried out by Direct PCR (without the extraction process). Bacterial colonies grown on TSA or NA medium were dried in physiological $\mathrm{NaCl}$ by taking 1 ose of bacterial colonies and slowly clouding it in a $\mathrm{NaCl}$ solution until the resulting turbidity is equivalent to 1 MacFarland standard. This solution was used as a DNA template.

\section{qPCR analysis}

Cycling and melt curve analysis was carried out using qPCR (QIAGEN 5 Plex) with the 2-step cycling method: Denaturation $95^{\circ} \mathrm{C}$ for 45 seconds and Annealing / Extention $60^{\circ} \mathrm{C}$ for 45 seconds. The primer for Salmonella typhimurium detection was InvA Forward primer (5'-ATC AGT ACC AGT CTT CTT ATC TTG AT-3 '), reverse (5'TCT GTT TAC CGG GCA TAC CAT-3'). The primer for
Listeria monocytogenes detection was the Forward primer (5 'CTA AAG CGC GAA TCT CCC TT 3'), reverse (5 'CCA TTG TCT TGC GCG TTA AT 3').

\section{Master mix solution}

Ten $\mu \mathrm{L}$ of master mix solution contained five $\mu \mathrm{L}$ Sybr green master mix, one $\mu \mathrm{L}$ forward primer, one $\mu \mathrm{L}$ reverse primer, one $\mu \mathrm{L}$ water-free RNase, and two $\mu \mathrm{L}$ DNA templates (Sophian et al. 2020).

\section{Positive Control}

Salmonella typhimurium ATCC 14028 phase 2, enriched in TSA or NA and scratched on the agar slant media, was used as a positive control. One ose of Salmonella typhimurium ATCC 14028 was taken and slowly clouded in physiological $\mathrm{NaCl}$ and equalized to 1 MacFarland standard.

\section{Negative control}

NTC (No Template Control) was used as a negative control that contained a master mix combined with primers and free nucleic acids water. The total negative control volume is ten $\mu \mathrm{L}$ consisting of $5 \mu \mathrm{L}$ master mix SYBR Green, one $\mu \mathrm{L}$ forward primer, one $\mu \mathrm{L}$ reverse primer, and three $\mu \mathrm{L}$ RNase free water (Sophian et al. 2020).

\section{Data analysis}

Data analysis was carried out based on two main criteria: Cycle threshold $(\mathrm{Ct})$ and melting point $(\mathrm{Tm})$. Cycle threshold $(\mathrm{Ct})$ analysis determines the sample's $\mathrm{Ct}$ value and compares it with the control. Melting temperature $(\mathrm{Tm})$ analysis determines the temperature at which $50 \%$ of double-stranded DNA changed to a single standard and compares the melting temperature to the melting temperature of positive control (Sophian et al., 2020).

\section{RESULTS AND DISCUSSION}

\section{Real-time PCR analysis}

Twenty-five processed meat samples were spiked with positive phase 2 bacterial standards control. The contaminated processed meat was analyzed by multiplex PCR to detect two bacterial targets in a single analysis. The results obtained as presented in (Table 1).

The analysis of 25 processed meat samples showed that all samples were positively contaminated with Salmonella typhimurium ATCC 14028 and Listeria monocytogenes ATCC 7644. It can be seen by comparing with the positive controls. The qPCR analysis results showed that positive control Listeria monocytogenes ATCC 7644 was detected at Ct 15.08, and Salmonella typhimurium ATCC 14028 was detected at $\mathrm{Ct}$ 18.50. The $\mathrm{Ct}$ values of processed meat samples were detected at 10.34 - 14.04. The negative control did not show any $\mathrm{Ct}$ value because the negative control was not amplified in the qPCR amplification process. 
Table 1. The results of the qPCR analysis

\begin{tabular}{lcc}
\hline qPCR analysis & Value & Tm \\
\cline { 2 - 3 } Negative control & - & - \\
Positive control Salmonella typhimurium ATCC 14028 & 18.50 & 85.20 \\
Positive control Listeria monocytogenes ATCC 7644 & 15.08 & 80.20 \\
Samples detected Salmonella typhimurium ATCC 14028 & 10.34 & 85.70 \\
Samples detected Listeria monocytogenes ATCC 7644 & 14.04 & 80.07 \\
\hline Nat
\end{tabular}

Note: $\mathrm{Ct}$ and $\mathrm{Tm}$ values are the average value of 25 data replications

\section{Cycling analysis $(\mathbf{C t})$}

The $\mathrm{Ct}$ analysis results showed differences in $\mathrm{Ct}$ values of samples detected by multiplex with two bacteria as positive controls. The $\mathrm{Ct}$ value of processed meat samples suspected to be contaminated with Listeria monocytogenes ATCC 7644 was 14.04, while the Ct value of samples contaminated with Salmonella typhimurium ATCC 14028 was 10.34 (Figure 1).

The Ct curve results can not indicate that processed meat samples are contaminated with pathogenic bacteria (Salmonella typhimurium or Listeria monocytogenes). It is because the Ct values are different, but it does not have a significantly different pattern (Figure 1). The amplification curve of the $\mathrm{Ct}$ value of positive control of bacteria with that of samples does not separate to form a pattern. The $\mathrm{Ct}$ value cannot differentiate species in real-time PCR analysis using multiplex techniques because the $\mathrm{Ct}$ value was influenced by DNA template concentration and purity. The same sample with different concentrations was detected at different $\mathrm{Ct}$.

\section{Melting temperature curve ( $\mathrm{Tm})$ analysis}

The results showed that processed meat samples suspected of contamination with Listeria monocytogenes ATCC 7644 have a Tm value of 80.7. Samples suspected to be contaminated with Salmonella typhimurium ATCC 14028 have a Tm value of 85.7 (Figure 2).

The $\mathrm{Tm}$ value in the qPCR analysis is influenced by the composition and size of the nucleotides. In the multiplex techniques, differences in composition and size of nucleotides are requirements for designing the primers. In the melt curve, fluorescence signals provide information on when double-stranded DNA bands begin to separate after annealing. The melt curve produces a specific single peak of each band. The presence of multiple peaks caused by differences in melt points can be used to differentiate bacterial species.

Figure 2 shows two patterns with two different shapes. The difference indicated differences in the melt curve pattern caused by the difference in the melting temperature (Tm) of different primers. This difference is the key to the success of melt curve analysis in multiplex detection.

Positive control Listeria monocytogenes ATCC 7644 (red curve) is formed at the melting point 80.7. In contrast, positive control Salmonella typhimurium ATCC 14028 (yellow curve) is formed at the melting point 85.7. These two melt points can be used as a reference in the sample to detect and differentiate contaminated samples with Salmonella typhimurium or Listeria monocytogenes.

\section{Discussion}

Detection of Salmonella typhimurium ATCC 14028 and Listeria monocytogenes ATCC 7644 in processed meat products using Multiplex Real-Time PCR (qPCR) was carried out by quantitative methods using a Quantinova SYBR Green (Qiagen) kit. Twenty-five processed meat samples were spiked with Salmonella typhimurium ATCC 14028 and Listeria monocytogenes ATCC 7644.

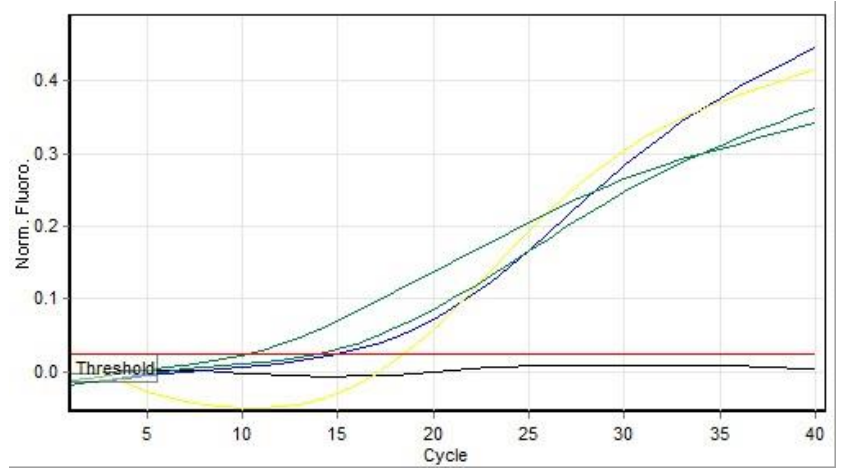

Figure 1: Curve of $\mathrm{Ct}$ amplification $\mathrm{qPCR}$ analysis. (blue: Listeria monocytogenes ATCC 7644), (yellow: Salmonella typhimurium ATCC 14028, (green: Sample)

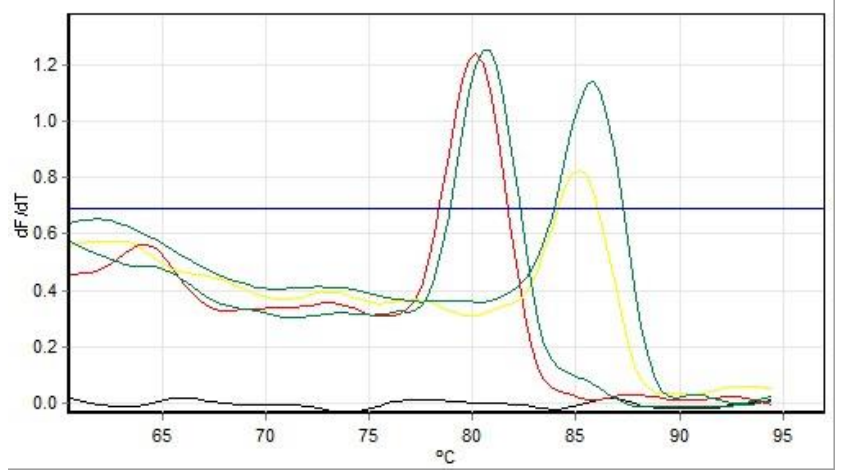

Figure 2: The melting curve of L. monocytogenes ATCC 7644, $S$. typhimurium ATCC 14028, and processed meat sample using the multiplex qPCR. (black: negative control; red: Listeria monocytogenes ATCC 7644; yellow: Salmonella typhimurium ATCC 14028; green: sample). 
This study used the PCR direct technique is, a molecular detection technique without the DNA extraction process. Samples originating from NA are then clouded and equalized to standard 1 MacFarland, used as DNA templates. The disadvantage of this technique is the presence of inhibitors so that their purity and concentration cannot be ascertained. However, this method has advantages in terms of time and cost because it does not require extraction kits and shortens the analysis.

McLauchlin et al. (2000), in their research on cream and cheese, revealed that type of matrix influences PCR readings. However, the results of this study showed that the matrix did not significantly affect DNA amplification. All the samples were enriched on TSA or NA growth media and then scratched on the selective media so that the growing colonies would be separated from the matrix.

It can be concluded that the real-time multiplex PCR method can be used to detect Salmonella typhimurium ATCC 14028 and Listeria monocytogenes ATCC 7644 using melt curve analysis (Tm). However, the $\mathrm{Ct}$ analysis cannot specifically reveal samples contaminated with Listeria monocytogenes ATCC 7644 or Salmonella typhimurium ATCC 14028, while the Tm value can be used to distinguish them. Further study needs to be done to determine the level of primary specificity mixed in one master mix formula.

\section{ACKNOWLEDGEMENTS}

The authors would like to thank the Head of the National Agency of Drug and Food Control (NADFC) in Gorontalo, Indonesia, for laboratory support.

\section{REFERENCES}

BPOM. 2019. Regulation of the Food and Drug Supervisory Agency Number 13 of 2019. Concerning the Limits of Contamination of the Food and Drug Supervisory Agency of the Republic of Indonesia. Jakarta. [Indonesian].

Chamberlain JS, Gibbs RA, Ranier JE, Nguyen PN, Caskey CT. 1988. Deletion screening of the Duchenne muscular dystrophy locus via multiplex DNA amplification. Nucleic Acid Res 16 (23): 1114111156.

Gosiewski T, Monika B, Heczko PB. 2012. The application of multiplex PCR to detect seven different DNA targets in group B streptococci. Folia Microbiol (2012) 57 (3): 163-167.

Hayden, MJ, Nguyen, TM, Waterman, A, Chalmers, KJ. 2008. Multiplexready PCR: a new method for multiplexed SSR and SNP Genotyping. BMC Genomics. 9: 80. DOI: 10.1186/1471-2164-9-80

McLauchlin J, Narayanan GL, Mithani V, Neill GO. 2000. The detection of enterotoxin and toxic shock syndrome toxin genes in Staphylococcus aureus by polymerase chain reaction. J Food Prot 63: 479-488.

Molina F, Acedo E.L. Rafael T, Isidro R, Antonia G, Jose R. 2015. Improved detection of Escherichia coli and coliform bacteria by multiplex PCR. BMC Biotechnol 15: 48. DOI: 10.1186/s12896-0150168-2.

Oliveira ACS, Matheus C Rosa, Jéssica LB, Yasmine AM, Milena MAF, Gabrielle Virgínia FC, Andréia SS, Roberta SS, Josyane BS, Fábio FL, Talita BR, Carina M. 2018. Validating the Efficiency of a Simplex PCR and Quantitative SYBR Green qPCR for the Identification of Salmonella spp. DNA. J Food Microbiol Saf Hyg 3: 1. DOI: 10.4172/2476-2059.1000130.

Sophian A. Purwaningsih R, Lukita B L And Cahyaningsih E. 2020. Detection of Salmonella typhimurium ATCC 14028 in supplement health product liquid preparation using Real-Time PCR (qPCR). Biofarmasi J Nat Prod Biochem 18: 61-65.

Sugiyoto, Kusuma A, Veronica W. 2015. Microbial content in beef from several traditional markets in Bandar Lampung. Integr Anim Husbandry Sci J 3 (2): 27-30 [Indonesian]. 